5 “Европа на пороге XXI века: ренессанс или упадок?” Под редакцией Пархалиной Т.Г. ИНИОН РАН, Москва, 1998.

${ }_{7}^{6}$ ст. 10 СПС. Там же, стр. 90.

7 "Правовой режим доступа российских товаров на рынок Европейского Союза", А.И. Шॉишаев. “Юридический мир” №7, 1998.

${ }^{8}$ Там же, стр. 28.

${ }^{9}$ Документы, касающиеся сотрудничества между ЕС и Россией, стр. 66.

10 “Юридический мир” № 8, 1998, стр. 20.

11 Там же, стр. 20.

12 Ст. 30 Документы, касающиеся сотрудничества между ЕС и Россией, cтp. 101.

${ }^{13}$ Ст. 30 (в) СПС. Там же, стр. 101.

14 Приложение 6 к СПС. Там же, стр. 163.

15 Приложение 7 к СПС. Там же, стр. 166.

16 Там же, стр. 168.

17 Там же, стр. 109.

18 Там же, п. 2 ст. 52 , стр. 116.

19 Там же, Приложение 9, стр. 171.

20 Там же, стр. 122-140.

21 “Европейский Союз: факты и комментарии”, №1, 1997.

22 “Европа на пороге XXI века: ренессанс или упадок ?” Под редакцией Пархалиной Т.Г. ИНИОН РАН, Москва, 1998.

\title{
ИНТЕГРИРОВАНИЕ РОССИИ В ЕВРОПЕЙСКОЕ ПРАВОВОЕ ПРОСТРАНСТВО (О ВЫПОЛНЕНИИ РОССИЕЙ ПРАВОВЫХ ОБЯ्ञЯАТЕЛЬСТВ ПЕРЕД СОВЕТОМ ЕВРОПЫ)
}

\section{C.A. $Г \circ р ш к о в ~ \mathrm{a}^{*}$}

Вступление в Совет Европы России (февраль 1996 года) и ее присоединение к основным европейским конвенциям по правам человека, стали важным этапом в утверждении в нашей стране системы защиты прав человека.

Несмотря на временное ухудшение отношений между Россией и Советом Европы в первой половине 2000 года и принятие его Парламентской Ассамблеей 6 апреля резолюции об ограничении полномочий российской парламентской делегации в связи с определенными нарушениями прав человека в ходе проводимой федеральной армией анти-

*андидат юридических наук. Подробнее об авторе см. № 3 нашего журнала за 1999 год. 
террористической операции в Чеченской Республике, наша страна не может находиться в какой-либо изоляции от Европейского сообщества. Россия принципиально заинтересована в том, чтобы устранить возникшие противоречия и продолжить конструктивное сотрудничество с Советом Европы, исходя из обших целей укрепления демократия, верховенства закона и соблюдения прав человека, интегрируясь в европейское правовое пространство.

Став членом Совета Европы, Российская Федерация для приведения своего законодательства в соответствие с европейскими нормами обязалась выполнить более трех десятков требований Европейского сообшества, причем значительную часть из них в течение года. Россия должна была: ратифицировать ряд европейских конвенций в области защиты прав человека; провести реформу судебной системы и прокуратуры, существенно улучшить условия содержания заключенных в тюрьмах и следственных изоляторах, перевести пенитенциарные учреждения в компетенцию Министерства юстиции Российской Федерации, ввести со дня вступления в Совет Европы мораторий на исполнение смертных приговоров и в течение трех лет отменить смертную казнь, ратифицировав Протокол № 6 к Конвенции о защите прав человека и основных свобод, принять закон об Уполномоченном по правам человека, внести изменения в законы о национальных меньшинствах, об основных политических свободах, о свободе вероисповедания, отменить несоответствующие европейским нормам запреты на свободное передвижение и выбор места жительства, признать в законодательном порядке право граждан, чьи права нарушены, на индивидуальное обращение в Европейский Суд по правам человека и обязательную его юрисдикцию (ст. 25 и 46 Конвенции о защите прав человека и основных свобод), выполнить другие требования, отвечаюшие правовым стандартам Совета Европы.

Выполнить такой значительный объем обязательств за сравнительно небольшой период нашей стране при всем желании было достаточно сложно. Для этого действительно нужно было осуществить серьезный прорыв в создании правовой базы по правам человека, соответствующей европейским требованиям, и значительно изменить правоприменительную практику.

Важное место в выполнении правовых обязательств России перед Советом Европы занимала и занимает ратификация основополагающих европейских конвенций, которые были подписаны при приеме в эту организацию или в последующие годы.

Среди них принципиальное значение имела ратификация нашей страной в марте 1998 года Конвенции о защите прав человека и основных свобод и Протоколов к ней (кроме Протокола № 6). Учитывая, что действующее российское законодательство имеет иное содержание, чем положения пунктов 3 и 4 статьи 5 Конвенции, Россия при ее ратификации в соответствии со статьей 64 Конвенции сделала оговорки по таким вопросам, как порядок ареста, содержания под стражей и задержания лиц, подозреваемых в совершении преступлений, дисциплинарные наказания в Вооруженных силах. Срок действия этих оговорок 
ограничен периодом, который потребуется пля внесения в законодательство Российской Федерации изменений, полностью устраняющих несоответствие ряда положений Уголовно-процессуального кодекса РСФСР, Гражданско-процессуального кодекса, Закона "О статусе военнослужащих" и других законов положениям Конвенции".

Благодаря созданной в 90-х годах фактически новой законодательной базе по правам человека, можно сказать, что уже во многом российское законодательство соответствует нормам Конвенции о зашите прав человека и основных свобод². Имеющиеся еще противоречия этим нормам должны быть устранены с принятием законодательных актов, проекты которых находятся на рассмотрении в Государственной Думе.

Так, в апреле 1997 года Государственная Дума приняла в первом чтении проект нового Уголовно-процессуального кодекса Российской Федерации. Однако, учитывая его несоответствие новым европейским обязательствам России, основную часть оговорок к Конвенции о защите прав человека и основных свобод, а также то, что изучение вопроса о соответствии законопроекта требованиям указанной Конвенции может осуществляться только на основе прецедентного права Европейского Суда (более 1300 вынесенных им решений), проект Уголовно-процессуального кодекса был направлен на международную экспертизу с привлечением экспертов Совета Европы ${ }^{3}$. Такая экспертиза была проведена. Европейские эксперты отметили значительное продвижение российских юристов-разработчиков в подготовке уголовно-процессуального законодательства с учетом современных тенденций в уголовной политике, в приведении уголовных процедур, отраженных в тексте проекта кодекса, в соответствие с состязательной моделью утоловного судопроизводства, принятой в большинстве европейских государств. Вместе с тем, эксперты выявили и значительное число положений, которые еще существенно расходятся с утвердившимися в европейских странах правовыми нормами в уголовно-процессуальной области. В частности, в вопросах, касающихся деятельности прокуратуры, апелляционного процесса, сроков предварительного заключения и других. Заключение юристов было в большей части учтено при подготовке проекта кодекса ко второму чтению.

До последнего времени России не удавалось решить законодательно вопрос о правовой отмене смертной казни в стране и ратифицировать Протокол №6 к Конвенции о защите прав человека и основных свобод. Кроме России, среди 41 страны - члена Совета Европы, Протокол № 6 также не ратифицировали, по данным на начало 2000 года, еще 5 государств: Албания, Болгария, Кипр, Польша и Турция. Из стран, кто ратифицировал этот Протокол в 1999 году, были Великобритания, Латвия и Литва. В начале 2000 года к ним присоединилась Грузия и Украина. Польша рассматривает вопрос о присоединении к указанному Протоколу.

Хотя в Конституции Российской Федерации, в Уголовном кодексе и Уголовно-исполнительном кодексе содержатся нормы о применении смертной казни в стране, однако, фактически Указом Президента Рос- 
сийской Федерации с 4 августа 1996 года осушествляется мораторий на применение смертной казни. Конституционный Суд Российской Федерации в своем постановлении ог 2 февраля 1999 года, учитывая, что во многих регионах страны нарушается право подсудимых на суд присяжных, ввел мораторий на вынесение смертных приговоров, а Президент Российской Федерации Указом от 3 июня 1999 года отменил исполнение всех уже вынесенных смертных приговоров в стране.

Вместе с тем, Россия не выполнила обязательство перед Советом Европы в этой области, не приняв закона об отмене смертной казни. На отношение российских парламентариев к этому вопросу оказывает влияние продолжаюшееся ухудшение криминогенной обстановки в стране и, в связи с этим, - непопулярность у подавляющей части населения идеи об отмене смертной казни. Однако, несмотря на это, Президент Российской Федерации внес в середине 1999 года в Государственную Думу на ратификацию Протокол № 6 к Конвенции, подписанный Россией 16 апреля 1997 года, и проект федерального закона "О внесении изменений и дополнений в некоторые законодательные акты Российской Федерации", направленные на отмену применения смертной казни в стране. Тем самым сделан еше один шаг в решении проблемы правовой отмены смертной казни в России.

В 1998 году Россия ратифицировала один из основополагающих европейских договоров - “Европейскую конвенцию по предупреждению пыток и бесчеловечного или унижающего достоинство обращения или наказания (1989 года) и Протоколы к ней"4. В ее основу положена статья 3 Конвенции о защите прав человека и основных свобод: “Никто не должен подвергаться пыткам и бесчеловечному или унижаюшему достоинство обращению или наказанию"5. Цель Конвенции по предупреждению пыток - помочь европейским государствам усилить защиту лиц, находящихся в местах лишения свободы. С учетом этого Конвенция по предупреждению пыток учредила Европейский Комитет по предупреждению пыток и бесчеловечного или унижающего достоинство обращения или наказания, который является внесудебным механизмом воздействия с целью предупреждения возможных физических или моральных злоупотреблений в отношении лиц, лишенных свободы, и эффективного надзора, контроля за обращением с такими лицами. Состав этого органа формируется из представителей государств-участников названной Конвенции. Он наделен правом направлять членов Комитета и его экспертов в любые места заключения либо содержания под стражей, находящиеся на территории государства-участника и при необходимости на основе установленных в докладе фактов давать рекомендации заинтересованному государству. "Комитет посредством посещений изучает обращение с лицами, лишенными свободы, с целью усиления, если это необходимо, защиты от пыток и от бесчеловечного или унижающего достоинство обращения или наказания"б.

Российское законодательство не препятствует реализации норм указанной Конвенции и наша страна готова оказать содействие любой проверке экспертов названного Комитета условий содержания заключенных в местах лишения свободы и изоляторах. Хотя за последние годы 
положение в них несколько улучшилось, но ситуация в целом остается неблагополучной.

Также в 1998 году Россия ратифицировала Европейскую хартию местного самоуправления (1985 года) ${ }^{7}$, включаюшую европейские требования о предоставлении права гражданам демократическим путем создавать органы местного самоуправления, действующие в рамках национального законодательства в интересах населения. Практически все ее положения отражены в таких федеральных законах, как "Об общих принципах организации местного самоуправления в Российской Федерации" (1995 года), “О финансовых основах местного самоуправления в Российской Федерации" (1997 года), "Об основах муниципальной службы в Российской Федерации” (1998 года) и в других. Однако, присоединение к Хартии обязывает российские государственные органы уделять большее внимание развитию и поддержке системы местного самоуправления и соблюдению права граждан участвовать в управлении делами на местах.

Определенные трудности возникли у нашей страны при ратификации Рамочной конвенции о защите национальных меньшинств (1995 года), которая была подписана при вступлении в Совет Европы (введена в силу для России с 1 декабря 1998 года). Это было вызвано тем, что ряд стран по-разному толкует понятие "национальное меньшинство".

Рамочная конвенция развивает положения статьи 14 Конвенции о защите прав человека и основных свобод, запрещающей дискриминацию национальных меньшинств, и содержит общие принципы и программные положения, которыми обязаны руководствоваться государства в целях защиты национальных меньшинств. Рамочная конвенция стала первым юридически обязывающим европейским документом по защите прав национальных менышинств, которая согласно ее статье 1 является неотъемлемой частью международной защиты прав человека и входит в сферу международного сотрудничества ${ }^{8}$. Выполнение положений Рамочной конвенции контролируется Комитетом министров Совета Европы.

При ратификации этой Конвенции Россией было сделано заявление, что она считает неправомочным включение в оговорки и заявления при подписании или ратификации Рамочной конвенции в одностороннем порядке определения термина "национальное меньшинство", которое не содержится в Рамочной конвенции. "По мнению Российской Федерации, попытки исключения из сферы действия Рамочной конвенции постоянно проживающих на территории государств - участников Конвенции лиц, ранее имевших грахданство, но произвольно лишенных его, противоречат целям Рамочной конвенции о защите национальных меньшинств"9. Российское заявление стало реакцией на заявление Эстонии при ратификации Рамочной конвенции (6 января 1997 года), которое исключает из понятия “национальное меньшинство” лиц, не признаваемых Эстонией гражданами.

Определение понятия "национальное меньшинство" представляет в России сложную задачу в силу наличия большого числа этнических 
групп, населяющих территорию нащей страны. Обычно в это понятие включают этнические группы, живущие за пределами своих национально-административных образований (территориальных автономий), этнические группы, не имеющие таких образований, а также представителей народов, имеющих государственные образования за пределами России.

В основном, можно сказать, что права национальных меньшинств защищены в российском законодательстве, прежде всего, в Конституции Российской Федерации, конституциях (государственных уставах) субъектов Федерации, в законах "О гражданстве Российской Федерации" (1991 года), “О языках народов Российской Федерации" (1991 года), "О реабилитации репрессивных народов" (1991 года), "Об образовании" (1992 года), "Основы законодательства Российской Федерации о культуре" (1992 года), а также непосредственно в Законе "О национально-культурной автономии" (1996 года) и друтих, которые содержат механизмы реализации прав менышинств и обязательства государства, в том числе финансовые.

На защиту прав малочисленных народов Российской Федерации, на сохранение и развитие культуры, традиционного образа жизни и на охрану их исконной среды обитания, хозяйствования и промыслов направлен Федеральный закон “О гарантиях прав коренных малочисленных народов России” (1999 года). Закон, в соответствии с Конституцией России, обшепризнанными принципами и нормами международного права устанавливает правовые основы гарантий самобытного социально-экономического и культурного развития коренных малочисленных народов страны и закрепляет их права на участие в формировании органов государственной власти, на самоуправление, на владение и пользование землей и друтими природными ресурсами, что необходимо для сохранения традиционного образа жизни ${ }^{10}$.

В 1999 году Россией была ратифицирована Европейская конвенция о взаимной правовой помощи по уголовным делам (1959 года) с рядом оговорок.

Одновременно с ней наша страна ратифицировала Европейскую конвенцию о выдаче от 13 декабря 1957 года, Дополнительный протокол от 15 октября 1975 года и Второй дополнительный протокол от 17 марта 1978 года к ней, которые создают международно-правовую основу взаимодействия государств для практического решения утоловно-процессуальных вопросов, связанных с выдачей лиц, совершивших преступления. При ратификации, как и при подписании, Россия сделала заявление и оговорки, по которым наша страна в соответствии со статьей 1 указанной Конвенции и с учетом требований российского законодательства и отечественной правоприменительной практики оставляет за собой право в некоторых случаях, обусловленных необходимостью защиты прав личности, отказать в выдаче.

Некоторые оговорки к двум вышеназванным европейским конвенциям учитывают то, что российское законодательство не содержит понятия “политические преступления", которые в европейских странах относятся к основаниям для отказа в выдаче и в оказании правовой 
помоши. Поэтому во всех случаях при решении вопроса об оказании правовой помоши наша страна не будет рассматривать в качестве "политических преступлений" ряд деяний, связанных с преступлениями против человечества, против жертв вооруженных конфликтов, с захватом воздушных судов, с захватом заложников и другими.

Верховный Суд и Генеральная Прокуратура Российской Федерации по просьбе учреждения иностранного государства, от которого исходит поручение о правовой помощи, решают вопрос о возможности применения процессуального законодательства при исполнении этого поручения, если оно не противоречит российскому законодательству ${ }^{11}$.

Правительство Российской Федерации уведомило Совет Европы о намерении ратифицировать и другой международный договор, затрагивающий основные права и свободы человека и обеспечивающий неотвратимость уголовного преследования и наказания лиц, совершивших террористические акты, - Европейскую конвенцию о пресечении терроризма (1977 года), и внесло ее на ратификацию в Государственную Думу в июне 2000 года. Конвенция (ее участниками являются более 30 государств) включает состав преступлений, связанных с незаконным захватом воздушных судов, с акциями, направленными против безопасности гражданской авиации, и целый ряд других преступлений. Конвенция определяет правовую основу для взаимодействия европейских стран по обеспечению борьбы с терроризмом и неотвратимости наказания террористов в соответствии с принципом: “выдай либо суди". Конвенция, в целом, не противоречит Конституции Российской Федерации и российскому законодательству. Вместе с тем, при ратификации Конвенции наша страна намерена сделать следующее заявление: "Российская Федерация исходит из того, что положения статьи 5 и пункта 2 статьи 8 Конвенции должны применяться таким образом, чтобы обеспечить неотвратимость ответственности за совершение преступлений, подпадающих под действие Конвенции, без ущерба для эффективности международного сотрудничества по вопросам выдачи и правой помощи". Такое заявление необходимо, поскольку указанные положения Конвенции могут быть использованы для неоправданного отказа в выдаче преступников или оказания правовой помощи.

Ратификация нашей страной блока так называемых образовательных конвенций способствует дальнейшему сближению и взаимодействию учебных учреждений России с учебными структурами европейских государств. Так, в 1999 году Россия присоединилась к Европейской конвенции об эквивалентности дипломов, ведущих к доступу в университеты (1953 года), Европейской конвенции об эквивалентности периодов университетского образования (1956 года), Европейской конвенции об академическом признании университетских квалификаций (1959 года), а в апреле 2000 года к Конвенции о признании квалификаций, относящихся к высшему образованию в Европейском регионе (1997 года). Последняя среди этих конвенций была подготовлена совместно Советом Европы и ЮНЕСКО и призвана заменить ряд действующих “образовательных" конвенций Совета Европы с учетом изменений, произошедших в образовательной сфере с 60-х годов. Кон- 
венция о признании квалификаций, относящихся к высшему образованию в Европейском регионе, создает механизм взаимного признания документов о высшем образовании вне зависимости от систем образования каждого из государств-участников и дает возможность их гражданам претендовать на профессиональную деятельность в друтих государствах.

По состоянию на июнь 2000 года Россия являлась членом 19 европейских конвенций, а включая Устав Совета Европы, Генеральное соглашение о привилегиях и иммунитетах Совета Европы и протоколы к нему и ряду конвенций -37 соглашений. Всего же Советом Европы было принято свыше 160 соглашений, в болышинстве которых участие нашей страны, по мнению соответствующих компетентных российских ведомств, признается целесообразным.

России предстоит ратифицировать и другие подписанные после вступления в Совет Европы конвенции. Среди них - Европейская конвенция о гражданстве (от 1997 года), в которой закреплены нормы, гарантирующие справедливость процедуры рассмотрения заявлений на приобретение гражданства. Конвенция исключает случаи дискриминации по национальному, религиозному и половому признаку при получении гражданства. Она содержит и такую гуманную норму, как освобождение лиц с двойным гражданством от воинской повинности в обоих государствах. Согласно Конвенции, подписанной Россией в ноябре 1997 года в Страсбурге, будут значительно облегчены условия принятия нового и возвращения утраченного гражданства, ограничена опасность его потери или лишения для бывших граждан СССР. Ратифицировав эту Конвенцию, Россия, с точки зрения международных норм, сохранит право самостоятельно определять, кто является ее гражданином ${ }^{12}$.

При приеме в Совет Европы в феврале 1996 года Россия обязалась изучить в целях ратификации Европейскую социальную хартию и проводить с момента вступления в эту организацию национальную политику в социальной области в соответствии с принципами, закрепленными в Хартии ${ }^{13}$. В Правительстве России рассматривается вопрос о подписании пересмотренной (новой редакции) Европейской социальной хартии.

Что касается основных принципов Европейской социальной хартии, то они не противоречат российскому законодательству. Фактически все названные в ней права, обеспечивающие социальную защиту человека, закреплены в Конституции и в других законодательных актах России. Например, Конституция Российской Федерации гарантирует социальное обеспечение по возрасту, в случае болезни, инвалидности, потери кормильца и в других случаях (ст. 39), право на охрану здоровья и медицинскую помощь (ст. 41) и другие социальные права ${ }^{14}$. Однако, многие из конституционных социальных прав продолжают оставаться декларативными в силу слабости социально-экономической политики государства. Поэтому необходимо добиться, чтобы зашита социальноэкономических прав человека и грахданина в нашей стране стала одной из главных функций государственной власти, соответствовала на прак- 
тике конституционному положению о Российской Федерации как о социальном государстве, политика которого создает условия для обеспечения достойной жизни и свободного развития человека.

Изменения социально-экономических отношений в стране в 90-х годах потребовали принятия блока социальных законов, направленных на защиту прав различных категорий населения. Среди них законы: “О занятости в Российской Федерации" (1991 года), “О коллективных договорах и соглашениях" (1992 года), “О порядке разрешения коллективных трудовых споров" (1995 года), “О ветеранах" (1995 года), “О социальной защите инвалидов в Российской Федерации” (1995 года), “О прожиточном минимуме в Российской Федерации" (1998 года), “О государственной социальной помощи” (1999 года), “Об основах охраны труда в Российской Федерации” (1999 года) и другие. Следует заметить, что реализация многих положений названных законов пока не обеспечивается достаточным бюджетным финансированием.

Особой проблемой остается повышение уровня обеспечения экономических и социальных гарантий для малообеспеченных групп населения до стандартов определенных Хартией. Необходимо устранить разрыв, который существует между закрепленными в законодательстве правами на экономическую и социальную зашиту и тем, как эти права реализуются в действительности и как обеспечиваются условия для утверждения достойной жизни и свободного развития человека.

К началу 2000 года не удалось решить такие проблемы, как несвоевременная выплата заработной платы, пенсий и социальных пособий, рост безработицы и неполной занятости. Конечно, на такие факты нарушения социальных прав в случае присоединения России к Хартии будет обращено внимание ее контрольными органами.

При ратификации Европейской социальной хартии (в редакции 1996 года) могут возникнуть определенные трудности в отношении применения отдельных пунктов статей. Например, пункта 2 статьи 12 (поддерживать систему социального обеспечения на удовлетворительном уровне, по крайней мере, достаточной для ратификации Европейского кодекса социального обеспечения 1964 года), пункта 4 статьи 13 (применять положения статьи о праве на социальную и медицинскую помощь на равных началах к своим гражданам и гражданам других государств-участников Хартии, которые законно находятся на территории соответствующего государства с учетом обязательств, вытекающих из Европейской конвенции о социальной и медицинской помощи, подписанной в Париже 11 декабря 1953 года) и пункта 4 статьи 6 (право работников и предпринимателей на коллективные действия в случае конфликта интересов, включая право на забастовку, за исключением обязательств, которые могут возникнуть из заключенных ранее коллективных договоров) ${ }^{15}$. Российское законодательство запрещает локаут (статья 19 Федерального закона “О порядке разрешения коллективных трудовых споров") ${ }^{16}$, который признается приведенным выше пунктом 4 статьи 6 Хартии.

При ратификации Хартии в соответствии с ее статьей “А” части III (Обязательства) Россия должна определить статьи и пункты, с которыми 
она будет считать себя связанной, и статьи и пункты, в отношении которых она не будет брать обязательства.

Хотя в целом в нашей стране сформировалась законодательная база, которая создает правовые предпосылки пля присоединения России к Хартии и последуюшего выполнения основных обязательств, предусмотренных ее статьями, вместе с тем, присоединение к этому договору потребует устранения некоторых неточностей и несоответствий в российских правовых нормах, усиления государственного и общественного контроля за соблюдением социального и трудового законодательства. Российским парламентариям предстоит также принять ряд законов, который позволил бы создать регулирующие механизмы реализации отдельных положений Хартии.

Несмотря на имеющиеся серьезные социально-экономические проблемы, несоответствие некоторых положений российского законодательства положениям Хартии, Россия заинтересована в том, чтобы подписать и ратифицировать ее. Чем быстрей произойдет включение нашей страны в практическое выполнение норм Европейской социальной хартии, тем активнее будет вестись работа по проведению социальной реформы, уточнению ее ориентиров, а, следовательно, и по дальнейшему утверждению на основе социально-трудового законодательства эффективной системы защиты экономических и социальных прав российских граждан.

Правительство Российской Федерации рассматривает вопрос о подписании Европейской Хартии региональных языков или языков меньшйнств (1992 года). Целью Хартии является содействие использованию региональных языков или языков национальных менышинств во всех сферах жизнедеятельности общества. Хартия содержит определение понятия “региональные языки или языки меньшинств” - “языки, которые традиционно используются на данной территории государства жителями этого государства, представляющими собой группу, численно меньшую, чем остальное население государства, и отличактся от официального языка (языков). Они не включат в себя ни диалекты официального языка (языков) этого государства, ни языки мигрантов". Однако, Хартия является достаточно сложным документом в связи с особой ее структурой и учетом общей языковой ситуации в отдельных государствах-членах Совета Европы. В Российской Федерации функционирует 150 языков, что значительно осложняет подготовку к подписанию этой конвенции. Вместе с тем, наша страна заинтересована в присоединении к Хартии, в части, которая защищает и способствует развитию использования региональных языков и языков меньшинств в области образования, культуры, средств массовой информации, судопроизводства, административного управления, в социальной, экономической и других сферах общественного развития.

Большинство включенных в ратифицированные и готовящиеся $\mathrm{k}$ ратификации конвенции требований, затрагивающих, прежде всего, основополагающие принципы и нормы в области защиты прав человека, учитывалось, как упоминалось выше, в процессе совершенствования российского законодательства. Принимаемые в стране федеральные 
конституционные и федеральные законы проходят юридическую экспертизу на предмет их соответствия европейским стандартам в области прав и свобод человека. Однако, остается еще проблема приведения в соответствие с международными и европейскими стандартами в области прав человека законодательства РФ, для чего необходимо внесение изменений в ряд действующих российских законодательных актов.

Вместе с тем, Президент Российской Федерации предпринял ряд действий в этом направлении и Указом (от 29 марта 1998 года) учредил должность Уполномоченного Российской Федерации при Европейском Суде по правам человека. Его основными функциями являются защита интересов Российской Федерации при рассмотрении в Европейском Суде по правам человека дел, возбужденных против Российской Федерации на основании Конвенции, изучение правовых последствий решения Европейского Суда для государств-членов Совета Европь и подготовка с учетом прецедентного права Совета Европы рекомендаций по совершенствованию законодательства Российской Федерации и правоприменительной практики. Уполномоченный должен также обеспечить взаимодействие федеральных органов государственной власти, органов исполнительной власти субъектов Российской Федерации и органов местного самоуправления при исполнении решений Комитета министров Совета Европы и Суда в связи с исками о нарушении Российской Федерацией своих обязательств по Конвенции, включая восстановление нарушенного права и выплату истцам денежной компенсации ${ }^{17}$.

За период с февраля 1996 года, с момента вступления в Совет Европы не удалось, как было записано в обязательствах России, реализовать некоторые другие требования. Например, не принят закон об альтернативной гражданской службе, отсутствует ряд законов, необходимых пля проведения судебно-правовой реформы и реформы прокуратуры.

Некоторые остаюшиеся проблемы, связанные с выполнением обязательств России перед Советом Европы (об основных политических свободах, об отмене запрета на свободное передвижение и выбор места жительства и другие), могли бы быть сняты и с принятием ряда законов, проекты которых находятся в течение нескольких лет на рассмотрении в Государственной Думе (например, о политических партиях, об оппозиционной деятельности, о собраниях, митингах, демонстрациях, шествиях и пикетированиях, о чрезвычайном положении, о военном положении и других).

Учитывая обязательства России перед Советом Европы, был принят Федеральный закон “Об уполномоченном по правам человека в Российской Федерации” и введен в действие в стране институт Уполномоченного по правам человека. Одним из направлений его деятельности является соблюдение прав человека в соответствии с международными нормами, в том числе со стандартами Совета Европы. Уполномоченный является членом межведомственной комиссии Российской Федерации по делам Совета Европы. Основными задачами комиссии является оказание содействия развитию сотрудничества нашей страны с Советом Европы и входящими в него государствами в целях совершенствования 
российского законодательства и правоприменительной практики в соответствии со стандартами Совета Европы, построения правового государства и углубления демократических реформ в России.

Вступление Российской Федерации в Совет Европы и участие в его деятельности, безусловно, способствуют развитию процесса демократических преобразований в стране и позволяет ей:

использовать с учетом своих особенностей наработанный в структурах Совета Европы информационный и консультативный инструментарий для осуществления реформы правовой системы, а также для приведения российского законодательства и правоприменительной практики, деятельности органов исполнительной и судебной власти в соответствие с европейскими правовыми стандартами, особенно в области зашиты прав человека;

постоянно поддерживать контакты с европейским сообществом посредством парламентской делегации, представителей Правительства, неправительственных общественных объединений в рабочих органах этой европейской организации, тем самым более активно влиять на ориентацию европейского сотрудничества в гуманитарной и правовой сферах, решение многосторонних программ и проектов Совета Европы, отстаивая свои государственно-национальные интересы;

добиваться повышения своего авторитета и устранения многого из того, что вызывало недоверие к ней со стороны других европейских государств.

Проведение в Российской Федерации правовой реформы и создание прӓвового гражданского общества с соответствующей структурой и механизмами защиты прав человека и его основных свобод с учетом европейских стандартов, участие в деятельности Совета Европы России - это отвечает, прежде всего, ее национальным интересам, вместе с тем, это является и весомым вкладом в развитие долгосрочного и стабильного европейского сотрудничества в области политики и безопасности, экономики и культуры, способствует динамичной интеграции России в сообщество стран Европы.

\section{itits}

С ратификацией Россией основных в области защиты прав человека европейских конвенций их нормы стали составной частью российской правовой системы. Они относятся, как и нормы других международных договоров, заключенных Российской Федерацией, $\mathbf{k}$ категории источников конституционного права России и имеют преимущество перед нормами федерального неконституционного и регионального законодательства. Вступление в Совет Европы и присоединение к европейским конвенциям стало важным шагом по пути нашей страны к утверждению правового обшества, вхождения в европейское правовое пространство и в конечном итоге к созданию такой системы защиты прав человека, которая обеспечивала бы подлинное соблюдение прав российских граждан.

Т См.: Федеральный закон “О ратификации Конвенции о защите прав 
человека и основных свобод и Протоколов к ней" // Собрание законодательства Российской Федерации (далее СЗ РФ). 1998. № 14. Ст. 2143.

2 О влиянии Европейской Конвенции о защите прав человека и основных свобод на российское законодательство см.: Горшкова С.A. Стандарты Совета Европы и законодательство России // Московский журнал международного права.1999. № 2. С.161-178.

${ }^{3}$ См.: Нужна помощь международных экспертов // Российская газета. 7 апреля $1998 \mathrm{r}$.

4 См.: Федеральный закон "О ратификации Европейской конвенции по предупреждению пыток и бесчеловечного или унижаюшего достоинство обращения или наказания и Протоколов к ней"// СЗ РФ. 1998. № 13. Ст.1466.

${ }^{5}$ См.: Конвенция о зашите прав человека и основных свобод // СЗ РФ. 1998. № 20. Ст.2143.

6 Европейская конвенция по предупреждению пыток и бесчеловечного или унижающего достоинство обращения или наказания // Международные акты о правах человека. Сборник документов. М., 1998. С.620.

${ }^{7}$ См.: Рамочная конвенция о защите национальных меньшинств // Международные акты о правах человека. Сборник документов. М., 1998. С.635.

${ }^{8}$ См.: Федеральный закон “О ратификации Европейской хартии местного самоуправления" // С3 РФ. 1998. №15. СТ.1695.

${ }^{9}$ Рамочная конвенция о защите национальных меньшинств // СЗ РФ. 1999. № 11. Ст.1256.

10 Федеральный закон "О гарантиях прав коренных малочисленных народов Российской Федерации” // СЗ РФ. 1999. №18. Ст. 2208.

11 Федеральный закон "О ратификации Европейской конвенции о взаимной правовой помощи по уголовным делам и Дополнительного протокола $\mathrm{k}$ ней” // С3 РФ. 1999. № 43. Ст. 5132.

12 См.: Европейская конвенция о гражданстве: Пер. с англ. МИД Российской Федеращии, 1997.

15 Заключение Парламентской Ассамблеи Совета Европы № 193/1996 "По заявке России на вступление в Совет Европы" // Право Совета Европы и Россия. Краснодар, 1996. С.86.

${ }_{14}$ См.: Конституция Российской Федерации. М., 1993. С.14-18.

15 См.: Европейская социальная хартия. Серия "Права человека". Выпуск № 2. М., 1998. С. 83, 84 и 74.

16 См.: Федеральный закон "О порядке разрешения коллективных трудовых споров” // С3 РФ. 1995. №48. Ст.4557.

17 Указ Президента Российской Федерации “О6 Уполномоченном Российской Федерации при Европейском суде по правам человека” // СЗ РФ. 1998. № 14. Ст.1540.

\section{г. Страсбург, Франция.}

Cmambr nоступила в редакцию в мае 2000 года. 